\title{
Orthostatic hypotension and vasodilatory peptides in bronchial carcinoma
}

\author{
M A Gosney, J R Gosney, M Lye
}

\begin{abstract}
Aim-To determine whether inappropriately secreted vasodilatory peptides have a role in the pathogenesis of orthostatic (postural) hypotension, a recognised paraneoplastic effect of bronchial malignancies usually attributed to immune mediated destruction of autonomic ganglia.

Methods-Serum concentrations of three vasodilatory peptides, atrial natriuretic peptide (ANP), vasoactive intestinal polypeptide (VIP) and calcitonin gene related peptide (CGRP), were measured in 111 patients with bronchial carcinoma and 35 controls prospectively screened for orthostatic hypotension $(>20 \mathrm{mmHg}$ drop in systolic blood pressure on repeated occasions on standing from the supine position) and in whom other causes of this condition were excluded.
\end{abstract}

Results-Twenty two (20\%) patients with carcinoma and two $(6 \%)$ controls had orthostatic hypotension according to the criteria used. Serum concentrations of ANP, VIP and CGRP were elevated above normal in, respectively, $25(23 \%), 10(9 \%)$ and eight $(7 \%)$ patients with carcinoma and in six $(18 \%)$, zero and three $(9 \%)$ controls. There was no correlation between orthostatic hypotension and concentrations of any of the vasodilatory peptides.

Conclusion-Elevated serum concentrations of ANP and CGRP were no more frequent in subjects with bronchial carcinoma than in controls and could not be attributed to the tumour, although there was a possible association for VIP. Orthostatic hypotension was more common in patients with carcinoma, but there was no evidence that the peptides measured played a role in its pathogenesis. (f Clin Pathol 1995;48:1102-1105)

Department of Geriatric Medicine, University of Liverpool, Liverpool, UK

M A Gosney

M Lye

Department of Pathology

J R Gosney

Correspondence to: Dr J R Gosney,

University Department of

Pathology, Duncan Building

Royal Liverpool University

Liverpool L7 8XW.

Accepted for publication

5 September 1995 Orthostatic hypotension is a recognised paraneoplastic effect of bronchial carcinoma, ${ }^{12}$ occurring in about $12 \%$ of patients with the disease. ${ }^{3}$ Although immunological injury to autonomic nerves is usually assumed to be responsible, ${ }^{4}$ it has been noted that paraneoplastic orthostatic hypotension is often not accompanied by other features of autonomic dysfunction, ${ }^{3}$ suggesting that its pathogenesis might not always be neuropathic. One al- ternative mechanism might involve one or more of a group of vasodilatory peptides occasionally secreted by malignant bronchial tumours. ${ }^{4}$ These include atrial natriuretic peptide (ANP), ${ }^{5}$ vasoactive intestinal polypeptide (VIP) ${ }^{6}$ and calcitonin gene related peptide (CGRP). ${ }^{7}$

The aim of the study was to assess the prevalence of orthostatic hypotension and of abnormal elevation of these three vasodilatory peptides in a series of subjects with bronchial carcinoma and to investigate the relation between them.

\section{Methods}

Patients ( $\mathrm{n}=111$ ) with newly diagnosed, histologically confirmed primary bronchial carcinoma and 35 age and sex-matched controls undergoing bronchoscopic examination, but in whom neoplasia was excluded, were studied. The mean age of the groups was 62 and 63 years, respectively. Of the group with carcinoma, 48 had squamous carcinoma, 16 adenocarcinoma, 16 non-small cell carcinoma which could not be typed further, and 31 had small cell tumours. ${ }^{8}$ Of the 35 control subjects, 10 had chronic bronchitis, nine pneumonia, three had bronchiectasis, and the remainder had no apparent pulmonary pathology.

A full history and examination were performed and biochemical data reviewed on all patients. Subjects were questioned about symptoms of orthostatic hypotension, specifically dizziness or fainting attacks, especially on standing from sitting or lying positions. A careful drug history was taken and any patients taking medication with a hypotensive effect, such as diuretics, anticholinergics, $\beta$-adrenoceptor blockers, sedatives, and angiotensin converting enzyme inhibitors, were excluded. Any subjects with clinical or laboratory evidence of disturbances of fluid and electrolytes which might have produced a hypotensive effect were excluded, as were those with diseases of the cardiovascular, endocrine or nervous systems, such as cardiac failure, diabetes mellitus or Parkinson's disease. No patients or control subjects were acutely ill at the time of assessment of blood pressure.

Supine and standing blood pressures were measured using an automated sphygmomanometer with an incorporated printer. Orthostatic hypotension was considered to be present when a drop of $20 \mathrm{mmHg}$ or greater in the systolic blood pressure occurred repeatedly, on separate occasions, on standing from the supine position. ${ }^{9}$ Then, after 15 minutes in a. 
Mean (SI) values and 95\% confidence intervals (CI) for serum concentrations of the three peptides measured

\begin{tabular}{|c|c|c|c|c|c|c|}
\hline \multirow[b]{2}{*}{ Subject group } & \multicolumn{2}{|l|}{$A N P$} & \multicolumn{2}{|l|}{$V I P$} & \multicolumn{2}{|l|}{ CGRP } \\
\hline & Mean (SD) & $95 \% C I$ & Mean (SD) & $95 \% C I$ & Mean (SD) & $95 \% C I$ \\
\hline $\begin{array}{l}\text { Controls without postural hypotension }(n=33) \\
\text { Controls with postural hypotension }(n=2) \\
\text { Patients with bronchial carcinoma without }\end{array}$ & $\begin{array}{l}145 \cdot 97(168 \cdot 87) \\
154 \cdot 5(118 \cdot 09)\end{array}$ & $0-477$ & $\begin{array}{l}24 \cdot 5(6 \cdot 01) \\
21 \cdot 67(2 \cdot 08)\end{array}$ & $12 \cdot 5-16 \cdot 4$ & $\begin{array}{l}115 \cdot 6(126 \cdot 0) \\
190 \cdot 3(172 \cdot 9)\end{array}$ & $0-363$ \\
\hline $\begin{array}{l}\text { postural hypotension }(\mathrm{n}=89 \text { ) } \\
\text { Patients with bronchial carcinoma and postural }\end{array}$ & $136 \cdot 2(213 \cdot 4)$ & $0-554$ & $28 \cdot 2(24 \cdot 0)$ & $0-75 \cdot 2$ & $106 \cdot 8(179 \cdot 9)$ & $0-459$ \\
\hline hypotension $(n=22)$ & $125 \cdot 05(81 \cdot 92)$ & $0-297$ & $26 \cdot 82(7 \cdot 01)$ & $12 \cdot 2-41 \cdot 4$ & $91 \cdot 1(125 \cdot 9)$ & $0-354$ \\
\hline
\end{tabular}

recumbent position, venous blood was drawn with a plastic syringe and immediately transferred to pre-cooled bottles, plastic in the case of CGRP and ANP which tend to adhere to glass, and all containing EDTA and aprotinin to inhibit degradation. After centrifuging at $500 \times \mathrm{g}$ for 15 minutes at $4^{\circ} \mathrm{C}$, serum was pipetted off and stored at $-85^{\circ} \mathrm{C}$ until assay, which was performed within 12 weeks.

The three peptides were measured using standard radioimmunoassay systems purchased from Incstar Corp., Minnesota, USA (ANP and VIP) and Peninsula Laboratories, California, USA (CGRP).

ANP was extracted using a Sepharose column containing C-terminal specific ANP antibody which was removed from the column with $0.025 \% \mathrm{HCl}$ and neutralised with $0.1 \mathrm{M}$ $\mathrm{NaOH}$. Sheep anti-ANP serum was added to the samples and standards and incubated overnight at $4^{\circ} \mathrm{C}$. Radiolabelled ANP was added to the tubes which were further incubated under the same conditions. Following this, sheep serum pre-precipitated with horse anti-sheep serum and polyethylene glycol were added to the tubes, which were centrifuged. Supernatant was decanted and the radioactivity of the residual pellet measured. The antibody used in the assay showed $100 \%$ cross-reactivity with ${ }^{1-28}$ human ANP, but none with adrenocorticotropic hormone (ACTH) or vasopressin. For assay of VIP, rabbit anti-VIP serum was added to samples and standards and incubated overnight at $4^{\circ} \mathrm{C}$. Radiolabelled VIP was added to the tubes which were further incubated under the same conditions. Following this, $0 \cdot 85 \%$ saline and normal rabbit serum pre-precipitated with goat anti-rabbit serum and polyethylene glycol were added to the tubes, which were centrifuged. The supernatant was decanted and the radioactivity of the residual pellet measured.

For assay of CGRP, rabbit anti-human CGRP serum was added to samples and standards and incubated overnight at $4^{\circ} \mathrm{C}$. Radiolabelled human CGRP was added to the tubes, which were further incubated under the same conditions. Normal rabbit serum and goat antirabbit serum were then added to the tubes, which were centrifuged. The supernatant was decanted and the radioactivity of the residual pellet measured. The antibody used in this assay has less than $0.001 \%$ cross-reactivity with calcitonin C-terminal peptide.

Various control procedures were performed to ensure accuracy of the results obtained. Thus, all serum samples were divided into aliquots before freezing so that repeated measurements of peptide concentrations could be made on the same sample, but using different kits. All assays were performed in duplicate so that any disparity between pairs of results could be quickly recognised and investigated and the assay repeated as necessary. Control serum samples containing known amounts of peptide were repeatedly assayed within and between different kits.

For all assays, radioactivity was measured with a Packard Crystal II gamma counter.

With these assay systems in our laboratory, normal serum concentrations were $<150 \mathrm{pg} /$ $\mathrm{ml}$ for ANP, $<40 \mathrm{pg} / \mathrm{ml}$ for VIP and $<300 \mathrm{pg} /$ $\mathrm{ml}$ for CGRP.

\section{Results}

The table shows mean values, standard deviations and $95 \%$ confidence intervals for serum concentrations of the three peptides measured.

Of the 111 patients with bronchial carcinoma, $22(20 \%)$ had orthostatic hypotension according to our criteria as did two $(6 \%)$ of the 35 controls. Serum concentrations of ANP were elevated above normal in $25(23 \%)$ patients with carcinoma and in six (18\%) controls. Of these 25 patients with carcinoma, five had orthostatic hypotension, but it was not found in any of the six controls. Serum concentrations of VIP were elevated above normal in $10(9 \%)$ patients with carcinoma, but in no control subjects. Two of the patients with carcinoma had orthostatic hypotension. Abnormally elevated concentrations of CGRP were found with about the same prevalence in both groups-that is, in three $(9 \%)$ of 35 controls and eight $(7 \%)$ of 111 patients with carcinoma. None of these three control patients had orthostatic hypotension, but it was present in one of the eight patients with carcinoma.

Although orthostatic hypotension was more common in patients with bronchial carcinoma than in controls, its presence did not correlate with elevated serum concentrations of vasodilatory peptides in either group. Nor, in the 22 patients with orthostatic hypotension and carcinoma, was it associated with any particular tumour type; 11 had squamous carcinoma, seven small cell carcinoma, two adenocarcinoma, and two non-small cell lesions which could not be typed further. Seven of the 10 patients with carcinoma in whom VIP concentrations were abnormally high had squamous carcinoma but, apart from this, there was no correlation between raised peptide concentrations and tumour type. 


\section{Discussion}

It is generally accepted that orthostatic hypotension may be considered to be present when a subject suffers a fall in systolic blood pressure of at least $20 \mathrm{mmHg}$ on standing from the supine position, consistently, on separate occasions. ${ }^{9}$ It has many causes, but is most often a feature of normal ageing, having been reported to be present in up to $24 \%$ of subjects over the age of 65 years, ${ }^{910}$ in whom it is usually attributed to physiological deterioration in autonomic function. ${ }^{3}$ Other causes include autonomic neuropathy, a reduced circulating blood volume or cardiac output, hyponatraemia, acute infection, and a range of drugs. ${ }^{911}$

In addition to the above, orthostatic hypotension also occurs as a paraneoplastic effect of bronchial carcinoma. ${ }^{1-3}$ Sometimes, it can be attributed to an effect of the disease, such as disturbances of fluids and electrolytes or non-specific severe debility, although it is generally considered to be caused by immune mediated autonomic neuropathy. ${ }^{4}$ This supposition is given some support by the observation of inflammatory and destructive changes in visceral autonomic nerves in paraneoplastic intestinal pseudo-obstruction, ${ }^{12}{ }^{13}$ although direct evidence for it is lacking and orthostatic hypotension in patients with bronchial carcinoma usually occurs unaccompanied by autonomic dysfunction elsewhere.

An alternative mechanism which has not been assessed as a possible cause of paraneoplastic orthostatic hypotension in patients with bronchial carcinoma involves the inappropriate secretion by the tumour in question of a peptide or peptides with vasodilatory effects. Of the broad range of amine, peptide and protein hormones secreted by bronchial malignancies, ${ }^{4}$ ANP, VIP and CGRP are the most likely to play a role in causing postural hypotension because of their vasodilatory properties. In this study, however, although orthostatic hypotension was certainly more common in patients with bronchial carcinoma than in controls, it could not be attributed to raised serum concentrations of the vasodilatory peptides studied. What, therefore, might it have been caused by? Disturbed metabolism of fluid and electrolytes or effects of vasodilatory drugs are an unlikely explanation, as patients with such confounding features were excluded from the study, as were those with cardiac, renal, nervous, or endocrinological disease likely to interfere with control of blood pressure. It may well be that the mechanism usually suggested, namely autoimmune damage to autonomic nerves, was indeed responsible. The prevalence of orthostatic hypotension in these patients, at $20 \%$, was somewhat greater than in the only comparable study of which we are aware, ${ }^{3}$ in which it was found in $12 \%$ of subjects with the disease, but a postural drop in systolic pressure of $30 \mathrm{mmHg}$ was the criterion for its diagnosis in that investigation, which may well account for the difference. Its prevalence in our control subjects, at $6 \%$, is consistent with previous investigations of its prevalence in subjects of this age. ${ }^{10}$
Our figures for the prevalence of raised serum concentrations of the three peptides measured in patients with bronchial carcinoma are difficult to comment on, because previous comparable investigations have been few and sometimes contradictory. For example, although activation of the gene encoding $\mathrm{ANP}^{14}$ and the peptide itself ${ }^{5}$ have been demonstrated in small cell tumours of the bronchus and raised serum concentrations have been described in occasional patients with small cell carcinomas, ${ }^{515}$ the overall prevalence of elevated concentrations in the serum of patients with bronchial carcinoma is unknown. In the present investigation, the fact that there was little difference between the two groups studied in this regard suggests that the elevation might have been unrelated to the presence of a bronchial tumour anyway; there are numerous stimuli to the secretion of ANP, physiological as well as pathological, which might have been responsible and some of the patients in the control group, although free from neoplastic disease, had a variety of inflammatory pulmonary conditions, which might have disturbed its secretion or metabolism. These comments apply equally well to CGRP, despite the fact that it has received more attention in this context than ANP. ${ }^{716}$ VIP has also been little studied in the context of bronchial neoplasia, although its inappropriate secretion by such tumours is well documented. ${ }^{6}$ Of the three peptides measured, only this one appeared to show a clear association with the presence of a bronchial neoplasm and it is of interest to note that, as in Said and Faloona's investigation, ${ }^{6}$ most of the tumours in patients with raised VIP concentrations were squamous.

The results of this study support previous observations that orthostatic hypotension is a paraneoplastic effect of bronchial neoplasia, but refute the hypothesis that inappropriately secreted vasodilatory peptides have a role in its pathogenesis.

We would like to thank colleagues at the Royal Liverpool University Hospital, Fazakerley District General Hospital and Glan Clwyd District General Hospital for allowing us to study patients under their care.

The work was part of a larger study supported by the North The work was part of a larger
West Cancer Research Fund.

1 Siemsen JK, Meister L. Bronchogenic carcinoma associated with severe orthostatic hypotension. Ann Intern Med 1963; 58:669-76.

2 Park DM, Johnson RH, Crean GP, Robinson JF. Orthostatic hypotension in bronchial carcinoma. BMF 1972;3:510-11.

3 Gould GA, Ashworth M, Lewis GTR. Are cardiovascular reflexes more commonly impaired in patients with bronreflexes more commonly impaired in pa

4 Gosney JR. Pulmonary Endocrine Pathology; endocrine cells and endocrine tumours of the lung. Oxford: ButterworthHeinemann, 1992.

5 Shimuzu K, Nakano S, Nakano Y, Audo M, Seki K, Kameda N. Ectopic atrial natriuretic peptide production in small cell lung cancer with the syndrome of inappropriate antidiuretic hormone secretion. Cancer 1991;68:2284-8.

6 Said SI, Faloona GR. Elevated plasma and tissue levels of vasoactive intestinal polypeptide in the watery diarrhoea syndrome due to pancreatic, bronchogenic and other tumors. N Engl F Med 1975;293:155-60.

7 Riley JH, Edbrooke MR, Craig RK. Ectopic synthesis of high Mr calcitonin by the BEN lung carcinoma cell line reflects aberrant proteolytic processing. FEBS Lett 1986; 198:71-9.

8 World Health Organization. The World Health Organization Histological Typing of Lung Tumors. Second edition. Am f Clin Pathol 1982;77:123-36.

9 Caird FI, Andrews GR, Kennedy RD. Effect of posture on blood pressure in the elderly. Br Heart $\mathcal{f} 1973 ; 35: 527-30$.

10 Rutan GH, Hermanson B, Bild DE, Kittner SJ, LaBaw F, 
Tell GS. Orthostatic hypotension in older adults. The Cardiovascular Health Study. CHS Collaborative Recardiovascular Health Study. CHS Collab.

11 Fine W. Some common factors in the causation of postural hypotension. Geront Clin 1969;11:206-15.

12 Schuffler MD, Baird HW, Fleming CR, Bell CE, Bouldi $T W$, Malagelada JR, et al. Intestinal pseudo-obstruction as the presenting manifestation of small cell carcinoma of the lung. Ann Intern Med 1983;98:129-34.

13 Chinn JS, Schuffler MD. Paraneoplastic visceral neuropathy as a cause of severe gastrointestinal motor dysfunction. Gastroenterology 1988;95:1279-86.
14 Bliss DP, Battey JF, Linnoila RI, Birrer MJ, Gazdar AF, Johnson BE. Expression of the atrial natriuretic factor Johnson BE. Expression of the atrial natriuretic factor
gene in small cell lung cancer tumors and tumor cell lines. gene in small cell lung cancer tumors

15 Manoogian C, Pandian M, Ehrlich L, Fisher D, Horton R Plasma atrial natriuretic hormone levels in patients with the syndrome of inappropriate antidiuretic hormone secretion. 7 Clin Endocrinol Metab 1988;67:571-5.

16 Craig RK, Edbrooke MR, Riley JH, McVey JH, Parker D. Differential expression of the human calcitonin-CGRP gene in medullary thyroid carcinoma and lung carcinoma cell lines. Recent Results Cancer Res 1985;99:71-8. 